Revista de Filosofía

Volumen 71 (2015) 79-92

\title{
APOLITICISMO Y CARENCIA DE MUNDANIDAD. ARENDT-HEIDEGGER
}

\author{
Marcos García de la Huerta \\ Universidad de Chile \\ marcosgh@adsl.tie.cl
}

\begin{abstract}
Resumen / Abstract
Heidegger nunca llama a la política por su nombre; escribe la palabra entre comillas, pues la "política" carece de verdad; pero su adhesión al nacionalsocialismo es consistente con sus ideas, sobre todo las relativas a la historicidad, la resolución y el destino del pueblo (Ser y tiempo, II, 4) ¿Quiere decir que la "política" carente de esencia se inviste de "verdad interna”? ¿Habría una filosofía nazi de verdad? La "animadversión (Abneigung) contra la política", que advierte Arendt en la mayoría de los filósofos, tiene una réplica en ella, manifiesta en su reserva frente a la filosofía, especialmente frente a la filosofía política. La relación de Arendt con Heidegger pasa por su despertar del sueño político y la experiencia de una pérdida de mundo. Este artículo analiza la relación entre ambos a la luz de la tensión entre filosofía y política, e intenta responder esas interrogantes y paradojas, a través de una discusión de las ideas de carencia de mundanidad (Unweltlichkeit) worldlessness) y de apoliticidad.
\end{abstract}

Palabras Clave: mundo, mundanidad, carencia de mundanidad, Arendt, Heidegger.

\section{APOLITICAL ETHOS AND WORLDLESSNESS. ARENDT-HEIDEGGER}

Heidegger never calls politics by its name; he always writes the word 'politics' in quotes because he thinks it lacks truth. His compromise with National-socialism is consistent with his philosophical ideas, mainly the ones concerning historicity, resolution and fate (Being and Time, II, 4). Does this mean that politics, lacking an essence, acquires an "internal truth"? Is there a truly Nazi philosophy? Arendt's response to the aversion against politics that she observes in most philosophers is replicated by her reserve with respect to philosophy, especially towards political philosophy. The relation of Arendt to Heidegger goes through an awakening from her political slumber and her experience of world loss. This essay analyses their relationship in light of the tension between philosophy and politics, and seeks to answer these questions and paradoxes by means of the ideas of wordlessness (Unweltlichkeit) and the a-political.

KEY WORDS: world, worldlessness, apolitical, Arendt, Heidegger

¿Por qué una teórica política como Arendt no pretende influir con sus ideas en los asuntos públicos y solo incidentalmente se involucró en la política activa, incluso rechazaba la idea de ser encasillada en el esquema de izquierda y derecha? A la pregunta: “¿Qué es usted? ¿Es conservadora? ¿Forma parte de los liberales? ¿En cuál 
de las opciones actuales se encuadra usted?", responde: "No lo sé, realmente no lo sé, ni lo he sabido nunca. Y supongo que nunca he asumido una de esas posiciones...la izquierda piensa que soy conservadora y los conservadores piensan a menudo que soy de izquierda [...] Pero debo decirle que el asunto me deja completamente indiferente. No creo que de esta manera las verdaderas cuestiones de este siglo vayan a recibir ninguna luz". Y agrega más adelante: "simplemente ocurre que no encajo en ninguna parte".

Con esa respuesta, se desmarca de la pregunta, cuyos términos no comparte. No es indiferencia hacia la política sino distanciamiento frente a la teoría política, que enmarca esas opciones. Arendt rechazaba el apoliticismo, veía un peligro en él, un síndrome autodestructivo, asociado a la "carencia de mundanidad" (worldlessness). Es cierto que ella solía definirse como una teórica de la política y rechazaba su adscripción "al gremio de los filósofos", pero eso significa que "no encaja" en la tradición de la filosofía política iniciada con Platón: no elabora teorías del Estado y la sociedad ideal; tampoco teoriza la política en la línea de Hobbes o de Rousseau. Se sitúa más bien en la tradición de pensadores políticos como Montesquieu y Maquiavelo, con quienes comparte una fundamental apertura a los fenómenos políticos.

A menudo Arendt contrapone la necesidad de comprensión a la teoría; ésta supone una separación o distancia con el objeto, característica del conocimiento científico, cuyo criterio de verdad es justamente, la objetividad. Esta concepción de la teoría renace en la época moderna con Descartes, para quien pensar y razonar son equivalentes, es decir, que cuando pensamos ejercemos una forma de racionalidad no comprometida, que corresponde a una facultad de la mente distinta del cuerpo, y que representa fielmente el orden de los objetos: de allí la afinidad del pensar objetivante con la razón instrumental. Para Arendt, en cambio, la realidad no es propiamente objeto sino un estímulo del pensamiento, una suerte de aguijón que lo pone en movimiento. La objetividad sirve de criterio para lo ya existente, pero el proceso de significación parte de la incertidumbre e indeterminación inherentes a lo aún no constituido, en pugna por constituirse; implica una acción productora de sentido que es esencialmente vinculante. El pensamiento no renuncia, sin embargo, a la imparcialidad: puede, mediante la imaginación, ponerse en el punto de vista del otro, y alcanzar lo que Kant llama un "pensamiento amplio"2.

Arendt precisa la especificidad del pensamiento cuando señala: "el pensar como tal nace a partir de los acontecimientos de nuestra vida y debe quedar vinculado a ellos como

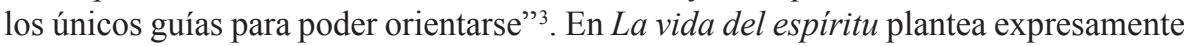
la pregunta: “¿Qué nos hace pensar?”. Y contrapone la respuesta griega de Platón [y de

1 Hannah Arendt, Lo que quiero es comprender, Trotta, Madrid, 2010. "Discusión con amigos y colegas en Toronto", p. 95. (Traducción en M. Hill (ed.), Hannah Arendt, The Recovery of the public World, St Martin's, New York, 1979, pp. 301-339).

2 Conferencias sobre la filosofia política de Kant. Paidós, Barcelona, 2003, p. 83. (Lectures on Kant's Political Philosophy. The University of Chicago Press, 1982).

3 Entre el pasado y el futuro. Península, Barcelona, 1996. Prefacio (Between Past and Future. Penguin Books, Nueva York, 1968). 
Heidegger], el asombro, con la romana de Epicteto y Boecio: la reconciliación. "Las dos fuentes del pensar que he tratado son distintas hasta el punto de contraponerse. Una es el asombro maravillado ante el espectáculo en medio del cual hemos nacido [...] la otra es la extrema miseria del ser humano de estar arrojado en un mundo cuya hostilidad es sobrecogedora" 4 . Se puede vivir sin teorizar, pero necesitamos comprender si queremos "conciliarnos" con el mundo. "Yo estoy interesada, primariamente en comprender, declara. Y quiero también conceder que hay otras personas que están, primariamente interesadas en hacer algo. Pero no es mi caso. Yo puedo vivir perfectamente sin hacer nada". Y enseguida aclara: "no conozco más reconciliación que el pensamiento".

El deseo de "reconciliación" y la experiencia personal no serían disociables: son personas, a fin de cuentas, las que piensan y se involucran en los asuntos del mundo. "El verdadero problema personal, dice Arendt, no fue lo que hicieron nuestros enemigos sino lo que hicieron nuestros amigos"6. Se refiere al surgimiento de un régimen asesino en el corazón de Europa, y a la adhesión que le prestaron muchos intelectuales. Entre esos "amigos" está, sin nombrarlo, pero en primerísimo lugar, Heidegger. Él adhirió a ese régimen, y Arendt jamás dudó que no fue por oportunismo corriente. Pero nunca pudo obtener de él una explicación acerca de los verdaderos motivos que lo llevaron a su compromiso político. Los descargos que hizo en Der Spiegel no son dignos de él y no consiguen persuadir más que a los convencidos. Arendt comparte con Aristóteles que la sabiduría del filósofo no coincide necesariamente con la sabiduría práctica que requieren los asuntos del mundo; por ende, cuando interviene en esos asuntos, las opiniones del filósofo no se distinguen de la de los hombres comunes. El problema consiste en que Heidegger intenta reconstruir filosóficamente la historia, incluida la historia política, de modo que la suya es una política esencial. Por tanto, no es un militante como cualquier otro: es el filósofo militante por excelencia. La "verdad interna" del nacional-socialismo, que reclama, solo él accede a ella. No fue, pues, un compromiso "circunstancial" con el nazismo ni una fascinación episódica con Hitler, precisamente, porque él no parte de lo político, para procurarle una caución filosófica sino que llega $a$ la política desde ideas previas desarrolladas en Ser y tiempo. Heidegger pretende que los griegos pudieron llegar a fundar la polis porque eran un pueblo apolítico, es decir, esencialmente ligado al ser. El nazismo se presentaba como "apolítico", aunque coronaba, en cierto modo, políticamente un "pensamiento sin suelo ni poder", del cual Heidegger pretende haberse "liberado"”.

4 La vida del espiritu. Paidós, Buenos Aires, 2002. (The Life of the Mind. Harcourt Brace, Nueva York, 1978, p. 162).

5 "Discusión con amigos y colegas en Toronto", Hannah Arendt Lo que quiero es comprender. Trotta, Madrid, 2010, p. 68.

6 Entrevista de Günther Gaus, Ensayos de comprensión. Caparrós Editores, Madrid, 2005, p. 27.

7 "Nos hemos liberado de la idolatría de un pensar sin suelo ni poder. Vemos el fin de una filosofía puesta a su servicio" ("Juramento al Estado Nacionalsocialista" y "Discurso 
El pensamiento nace, pues, según Arendt, de la experiencia y permanece vinculado a ella. Todo comienza para ella con ese golpe brutal-el incendio del Reichstag-y sigue con el terrorismo del Estado racial: "Desde ese momento me sentí responsable", dice Arendt: era el despertar del sueño político. "Fue como si se hubiera abierto un abismo", agrega [...] "lo sucedido, es algo que ninguno de nosotros logrará nunca quitarse de encima"; "hizo trizas nuestras categorías de pensamiento y nuestras criterios de juicio moral"s.

¿Cómo podría, sin embargo, ser restaurador el pensamiento, si él mismo está "hecho trizas"? Admitiendo que no se puede restaurar el mundo solo con teorías o con perdón; y concediendo también que el intento de reconciliación es solo un "ejercicio de pensamiento político", ¿por qué desmarcarse de la filosofía, si el anhelo de reconciliación es lo que mueve el pensamiento? ¿No es precisamente en la filosofía donde Arendt mejor "encaja"? ¿Por qué no decir: "no conozco más reconciliación que la filosofía"?

Porque la filosofía es parte del problema, precisamente; "la filosofía algo tiene que ver en este lío", como ella dice. Por una parte, hay esa tensión o conflicto entre la filosofía y la política, y en general, entre la vida contemplativa y la vida activa, un tema recurrente y central ${ }^{10}$. Pero "esa tensión no se da en la filosofía de la naturaleza. El filósofo se sitúa frente a la naturaleza como todos los demás seres humanos; cuando reflexiona sobre ella, habla en nombre de toda la humanidad. En cambio, frente a la política el filósofo no tiene una postura neutral ¡No desde Platón! Hay una suerte de animadversión contra toda la política en la mayoría de los filósofos, con muy pocas excepciones. Kant es una de ellas. Esta animadversión es de extraordinaria importancia [...], pues no se trata [solo] de una cuestión personal. Está en la esencia de la cosa misma $[. .$.$] quiero contemplar la política, por así decirlo, con ojos no enturbiados por$ la filosofía"11.

¿Quién ha contemplado la política "con ojos enturbiados por la filosofía"? Desde luego, Heidegger; y entre los filósofos ¿quiénes muestran esa animadversión contra la política? De nuevo, en primer lugar, hay que mencionarlo a él: no por ser el único ni el más importante, sino porque ese prurito de desrealizar la política, de negarle espesor propio, esa manía suya de poner la palabra entre comillas, apunta a una dificultad en la relación con la política. Admitiendo que la filosofía tuviera por función mostrar lo oculto al entendimiento común, ¿por qué tendría que intervenir el filósofo en la política? El problema no es que Heidegger adhiriera al régimen nazi, sino cómo lo hizo.

rectoral”, en M. García de la Huerta, La técnica y el Estado moderno. Edeh, Santiago 1980, p. 48. Ver también el "Discurso rectoral", op. cit., pp. 27 ss.).

$8 \quad$ Entre el pasado y el futuro, op. cit., Prefacio.

$9 \quad$ Así llama en el Prefacio de Entre el pasado y el futuro a las reflexiones contenidas en ese libro.

10 Filosofía y política, Besataria, Bilbao, 1997. En La promesa de la política, Paidós, Barcelona, 2008, pp. 43-75 (Philosophy and Politics, en Social Research, Vol. 71, núm. 3, 2004).

11 “QQué queda? Queda la lengua materna”, en Ensayos de comprensión, op. cit., página 18. 
Si hubiera aceptado la rectoría por debilidad, por prudencia o lo que fuera, el asunto habría quedado ahí, quizá habría movido a más de algún reparo de orden moral, pero "la cuestión" no habría dado para mucho más: "que alguien por tener mujer e hijos que cuidar, se uniformase (Gleichschaltung), era algo que nadie podía tomarse a mal. ¡Lo malo es que algunos llegaron a creérselo realmente! [...] ¡Pero, esto significó que se hicieron ideas sobre Hitler, y en parte eran cosas terriblemente interesantes! ¡Cosas fantásticamente interesantes y complicadas! Que flotaban muy por encima del nivel común de la gente. Esto, yo lo encontraba grotesco. Hoy diría que cayeron en la trampa de sus propias ideas" 12 .

La metáfora de la "trampa" es la misma que ella emplea en el artículo "Heidegger el zorro", escrito con ocasión de los 80 años del filósofo; el "zorro" cae en su propia trampa significa que quedó atrapado en sus ideas, en su modo de entender la política, al margen de toda deliberación. No fue por ingenuidad profesoral, tampoco un delirio infantil, como quiso presentárselo Jaspers, quizá para tratar de sonsacarle una explicación: "usted pareció conducirse frente a los fenómenos del nacionalsocialismo como un niño que sueña", le escribe ${ }^{13}$. "Niño soñador" no es la imagen que mejor le calza, tampoco la de Herr Professor distraído. Quizá la de "aprendiz de brujo", a juzgar por esas ideas "fantásticamente interesantes sobre Hitler", y su mágica identificación con el "destino alemán". Igualmente delirante resulta la afirmación: "el Führer mismo y solo él es la realidad alemana presente y futura y su ley" ${ }^{14}$. Para entender estas afirmaciones se requeriría de una lectura nazi de Ser y tiempo.

Al tenor de las declaraciones y descargos en Der Spiegel se advierte que Heidegger imaginó el nacionalsocialismo, junto con varios otros intelectuales alemanes de primera línea -Carl Schmitt, Ernst Jünger y Arnold Gehlen, entre ellos-, como el comienzo de la "revolución alemana". A diferencia de la francesa, ésta sería nacional y socialista o, mejor, pangermanista y popular (völkisch). En todo caso, no liberal y parlamentarista. El parlamento bien puede ser el templo de la habladuría; y un sistema de partidos pulverizado como el alemán de los años veinte no impedía que se agruparan en un esquema bipolar, funcional al statu quo y más estable que un escenario multipolar; más confiable también, porque garantiza los equilibrios y permite que la política funcione como un juego de balancín: uno y otro necesitan sostenerse sobre el balancín, porque

12 “Qué queda? Queda la lengua materna”. En Ensayos de comprensión..., op. cit., p. 28. La foto oficial de Heidegger rector señala al pie que fue "elegido rector siguiendo el dispositivo de la Gleichschaltung", del alineamiento con el régimen. Emmanuel Faye, Heidegger, L'introduction du nazisme dans la philosophie. Albin-Michel, Paris, 2005, pp. 116 y 156.

13 En carta del 19-III-1950. Heidegger Correspondance avec Karl Jaspers 1920-1963. Gallimard, Paris, 1996, p.180 (Briefwechsel 1920-1963, V. Klosterman, Francfort y R. Piper, Munich, 1990).

14 Ser y tiempo, FCE, México, 1951; M. García de la Huerta, La técnica y el Estado moderno, Edeh, Santiago 1980, p. 45ss. El libro de Faye arriba citado, muestra que la actividad de Heidegger antes y después de 1933 se desarrolló dentro de una red de relaciones y con propósitos claramente políticos. 
la permanencia de uno condiciona la del otro y beneficia a ambos. Hitler le saltaba a la yugular a ese sistema, rompía el statu quo y el esquema de izquierdas y derechas: una situación propicia para idear cosas "fantásticamente interesantes". Heidegger se imaginó un despertar: la irrupción del Geist, la promesa del fin del imperio de la razón calculadora y el clarear de un nuevo comienzo (Aufbruch). La "resolución" del Führer, la promesa de una renovación de la universidad en el marco de la revolución alemana y la rectificación del curso declinante de Occidente, terminaron por fascinar a Heidegger. "Por oscuras y problemáticas que puedan parecer muchas cosas, no puedo menos que sentir cada vez más [...] que una época ha envejecido. Todo queda suspendido de la cuestión de saber si preparamos el sitio para que la filosofía pueda jugar su papel y le procuramos el verbo que requiere", escribe a Jaspers ${ }^{15}$.

Hay una convicción profunda en estas palabras. La retórica oficial, demasiado tosca, en opinión de Jaspers, le induce a éste a preguntar: "¿Cómo un hombre tan inculto como Hitler puede gobernar Alemania?", y Heidegger le responde escuetamente: "la cultura no tiene importancia" ${ }^{16}$. Hitler y sobre todo sus acólitos eran "gente demasiado indigente en cuanto al pensar" y, por lo mismo, Alemania requería de un conductor espiritual (geistige Führershaft) ¿Quién mejor que él podía "procurar el verbo" y asumir la conducción espiritual?

La interpretación de Heidegger de la derrota francesa en 1941 es ilustrativa de su modo de pensar: "En estos días nosotros somos testigos de una ley misteriosa de la historia, la de que llega un día en que un pueblo ya no está a la altura de la metafísica que ha brotado en su propia historia, lo cual sucede precisamente en el instante en que esa metafísica se ha vuelto a lo incondicional... No basta con tener tanques, aviones y aparatos para la difusión de noticias... Se requiere de un tipo de hombre que desde su base sea adecuado a la singular esencia fundamental de la técnica moderna y su verdad metafísica, es decir, que se deje dominar enteramente por la esencia de la técnica... Solo el sobrehombre en el sentido de la metafísica de Nietzsche es adecuado a la incondicional "economía maquinal" y, a la inversa: el sobrehombre necesita de tal economía para la instauración del dominio incondicional de la tierra" ${ }^{17}$.

En el mismo artículo antes citado -"Heidegger octogenario"-, en una nota al pie, Arendt agrega algo más sobre la caída del "zorro" en la trampa: "Aquello en que consistió ese error se diferencia considerablemente de lo que entonces se consideraban “errores”. ¿Quién, aparte de Heidegger, llegó a la idea de ver en el nacionalsocialismo 'el encuentro del hombre moderno con la técnica, definida a nivel planetario?', [...] más

15 Correspondance avec Karl Jaspers 1920-1963, Gallimard, Paris, 1996, 3 de abril de 1933, p. 138.

16 Correspondence avec Karl Jaspers 1920-1963. Gallimard, Paris, 1996, Nota 117, p. 409.

17 Heidegger, Nietzsche. Neske, 1961, II, pp. 165-166. 
decisivo es el encuentro con la realidad en los sótanos de la Gestapo y en las cámaras de tortura de los campos de concentración" ${ }^{18}$.

Estas palabras, seguramente las agregó Arendt con posterioridad. Se trataba de celebrar su cumpleaños, no de arruinarle la fiesta. En muy contadas ocasiones, por demás, ella se pronunció abiertamente y sin tapujos sobre este asunto. Casi siempre lo hace con gran moderación y cautela, al punto de merecer la crítica de mantener una "lealtad ciega" (Sheldon Wolin) con Heidegger. Pero en el cuerpo del mismo escrito lanza una crítica del mismo calibre: "Nosotros que queremos honrar a los pensadores, aun cuando nuestra posición está en el mundo, difícilmente podemos encontrar sorprendente y enojoso que Platón, lo mismo que Heidegger, recurriesen a los tiranos y a los Führers, puesto que se comprometieron en los asuntos humanos. Ello no puede deberse a circunstancias personales y menos aún a un carácter preformado, sino más bien a lo que los franceses llaman una déformation professionelle"19.

La filosofía platónica no es inocente, "naturalmente no en el sentido de que Hitler tenga algo que ver con Platón. Más bien diría en el sentido de que la filosofía occidental no ha tenido nunca un concepto claro de la realidad política, y no podía tener uno, ya que, por necesidad, ha hablado del hombre y solo tangencialmente se ha ocupado de la pluralidad" 20 . Refiriéndose a lo mismo trece años más tarde, reitera: "Mi opinión era que lo ocurrido tiene que ver con esta profesión [...] Hablo en pasado. Hoy sé más al respecto" ${ }^{21}$. "Sabe más", porque continuó pensando en el asunto: sabe que la política ¡sí que tiene realidad! Y no puede hacerse de cualquier manera; no puede ser teologizada, lo que implica una devaluación de los asuntos humanos, tampoco puede ser militarizada, pues eso suprime la acción deliberativa; y no puede ser economizada impunemente, porque no se reduce a la pura administración. Sobre todo, no puede ser cabalmente filosófica: la política no está ni debe estar sujeta a la filosofía; gobernar no es tarea de los filósofos. No significa que sea "irracional", pues requiere del diálogo y la deliberación. Pero no es cientifica en el sentido de la teoría predictiva ni es monológica como la teoría deductiva; no se hace de a uno como el pensamiento. El conflicto le es inherente también la incertidumbre porque se hace entre muchos y está sujeta a los vaivenes del azar.

Cuando Arendt se volvió a encontrar con Heidegger tras largos años de exilio, quiso saber cómo había él procesado su "error"; e intentó reanudar un diálogo sobre "la cuestión" y obtener una explicación suya, especialmente sobre el Holocausto y la

18 “Martin Heidegger Octogenario", Revista de Occidente No 84, marzo 1970. (Subrayado por mí) "Heidegger el zorro", Diario filosófico, Cuaderno XVII, [7], julio de 1953 ("Heidegger the fox", Essays in Understanding 1930-1954, John (Comp.) Schocken Books, Nueva York, 2005).

19 Martin Heidegger Octogenario, op. cit., p. 270.

20 Hannah Arendt, Correspondence Kohler \& Saner eds., Harcourt Brace Jovanovich, Nueva York, 1992, 4-III-51, p. 166.

21 “¿Qué queda...? Op. cit., p. 28. 
tragedia alemana. La respuesta, dice así: "el destino de los judíos y de los alemanes tiene su propia verdad que nuestro cálculo histórico no puede alcanzar. Si el mal, lo que ha acontecido y acontece, es, entonces solo a partir de allí asciende el Ser al misterio y se vuelve inaccesible para el pensar y el soportar humanos, por el hecho de que algo sea no significa que es de por sí lo bueno y lo recto. Pero tampoco puede ser una añadidura a lo real aducida moralmente, por la voluntad humana" 22 .

Todos las conjugaciones del verbo "ser" van aquí en cursivas, lo mismo que veintitantos años antes el "es" referido al Führer. Después de esta insólita "explicación" sobre el "ascenso del Ser al misterio", con la que debía recuperar la confianza de su amiga, Heidegger agrega, incrédulo quizá él mismo de la capacidad persuasiva de su explicación: "no estoy familiarizado con lo político ni tengo talento para ello"23.

Arendt terminó mofándose de estas extravagancias. En una carta a Jaspers de 1949, escribe: "Esa vida que lleva en Todtnauberg, esa carga contra la civilización, escribir Seyn con "y" griega, todo eso es en realidad una ratonera". Quizá fuese también una muestra de humor negro, escribir Seyn con "y" griega, justamente cuando Alemania quedaba fuera de juego. La falta de juicio político, en todo caso, indica una carencia de sentido para una dimensión esencial de la realidad humana, y también falta de gusto.

La cuestión del gusto reviste significado político, al asociarse con el juicio, una facultad que Kant aborda en su Crítica del juicio, titulado inicialmente Crítica del gusto (Kritik des Geschmacks). Contra la idea corriente, según la cual "en gustos no hay nada escrito" o "no corresponde discutir acerca de gustos", Kant piensa que sí es posible fijar criterios estéticos referentes al buen (o mal) gusto ${ }^{24}$. A pesar de que Kant nunca escribió una filosofía política y los escritos que se suele considerar como "políticos" son más bien de filosofía de la historia, Arendt sostiene que habría una filosofía política implícita, dispersa en su obra. Kant conseguiría rebasar esa tensión -predominante en la tradición-, entre filosofía y política, porque no comparte esa "animadversión" hacia la política, que caracteriza a la mayoría de los filósofos. Evaluar situaciones singulares, como hace el juez, el historiador o quienes actúan, "requiere de un talento peculiar que solo puede ser ejercitado, no enseñado" 25 . El juicio estético, análogamente, no se basa en algún concepto o regla que permita deducir si un objeto -este cuadro, por ejemplo, Las Meninas- es bello o feo, sino que es, como suele decirse, "cuestión de gusto". Pero Kant entiende, al mismo tiempo, que el gusto es intersubjetivo, susceptible de comunicar: está basado en un sentido común (gemeiner Menschenverstand). La formación de juicios singulares o referidos a situaciones o casos concretos se cumple, pues, a través de un proceso genuinamente discursivo, basado en lo que Kant llama "mentalidad 90 .

23 En la misma carta del 12 de abril de 1950.

24 Conferencias sobre la filosofia politica de Kant. Paidós, Barcelona, 2003.

25 "El juicio" era el título de la tercera parte de La vida del espiritu, la última obra de Arendt, que quedó inconclusa a causa de su muerte. 
amplia", o sea, la que resulta de confrontar el juicio propio con el de otros, de ponerse imaginariamente en su punto de vista, o/y de tomar en cuenta a los otros ausentes.

Contra la tesis de Arendt juega el hecho de que Kant no enuncie en términos de politicidad las cuestiones fundamentales que llevan a filosofar; están referidas al sujeto, independientemente de su ser con otros. Incluso el “¿qué debo hacer?" se refiere al hombre como ser moral, no como ser político. Puede considerarse que los otros están implícitos en esta pregunta, porque no tendría sentido regular la propia conducta si no es en relación con los demás. En el imperativo categórico, por ejemplo, la intersubjetividad está tácita, pues el criterio de validez de la norma que ha de regir mi acción exige que ella sea válida para todos. En cualquier caso, la idea de pluralidad está ausente en Kant, y lo que informa las tres cuestiones es el interés propio, no el interés por el mundo, que caracteriza la política ${ }^{26}$.

Por otra parte, sin embargo, Kant reaccionó hacia el final de su vida contra el moralismo de la Crítica de la razón práctica: comprendió que el verdadero problema era constreñir al hombre a "ser un buen ciudadano aunque no esté obligado a ser moralmente un hombre bueno". Un Estado debe constituirse de modo que funcione aun para "una raza de demonios". "No es la moralidad... causa de la buena constitución del Estado, sino más bien al contrario; de esta última hay que esperar la formación moral de un pueblo" El hombre de bien solo puede ser buen ciudadano en la ciudad buena o bien constituida ${ }^{27}$.

A pesar de coincidir con Platón en ciertos aspectos, Kant tiene dos divergencias fundamentales con él. La primera se refiere al significado de la sensibilidad y del cuerpo. La "Crítica de la razón pura ha sido definida con toda justicia como una defensa, una apología de la sensibilidad humana. Ni siquiera en su juventud, cuando... manifestó cierta hostilidad platónica frente al cuerpo... llegó a afirmar que el cuerpo y los sentidos fuesen la fuente principal del error y del mal" ${ }^{28}$. La otra divergencia con Platón, se refiere a la disposición frente a los hombres comunes y sus derechos. Kant afirma que Hume lo despertó de su "sueño dogmático" y Rousseau de su sueño moral. Arendt agrega que la Revolución francesa lo despertó de su sueño político. El pasaje donde Kant reconoce su deuda con Rousseau dice así: "yo mismo soy por gusto un investigador. Siento toda la sed por el conocimiento y la inquietud por conocer cada vez más, así como también el contenido que hay en todo progreso. Algún tiempo pensé que todo esto podía constituir el honor de la humanidad y despreciaba a la plebe que no sabe. Pero Rousseau me ha traído a lo que es recto. Esta prerrogativa deslumbrante desaparece, aprendo a honrar a los hombres, y me encontraría a mí mismo más inútil que los trabajadores comunes si no creyera que esta consideración puede participar a todos los demás un valor para restablecer de nuevo los derechos de la humanidad" 29 .

26 Conferencias sobre la filosofia política de Kant. Paidós, Barcelona, 2003, pp. 44-45.

$27 \quad$ Hacia la paz perpetua. Editorial Ladosur, Buenos Aires, 2004.

28 Conferencias sobre la filosofía política de Kant. Paidós, Barcelona 2003, p. 57.

29 Conferencias sobre la filosofía política de Kant, op. cit., p. 59. 
Con el abandono de la jerarquía entre el sabio y los no sapientes, desaparece la base misma del conflicto entre filosofía y política, pues esta tensión deriva precisamente de la ilusión platónica de subordinar la política a una idea o teoría.

Kant no comparte la pretensión imperial de la filosofía platónica, con lo cual desaparece también el conflicto con la política. No menos significativo que su despertar del sueño social es su despertar del sueño político. Este último se asocia a un acontecimiento singular que reviste significado universal. El júbilo que desató en el mundo el estallido de la Revolución en Francia llamó poderosamente su atención. ¿Por qué ese entusiasmo? ¿Cómo juzgar este evento singular? Kant distingue la óptica de los observadores y la de los actores. Admite que la Revolución es condenable porque infringe la legalidad existente. Sin embargo, el entusiasmo de los observadores -entre los cuales él se incluye-, no es capricho ni está dictado por el egoísmo o el interés: responde a un gusto contemplativo o pasividad placentera (untätiges Wohlgefallen). Como "ciudadano del mundo" o como "espectador del mundo", el filósofo ve lo que el acontecimiento representa desde un punto de vista universal, y los gobernantes "harían bien en consultar" su opinión. Este rango especial atribuido a la observación exime, en cierto modo, al filósofo de la necesidad de intervenir en la política, de otra manera que no sea haciendo "uso público de la razón". Kant se libra de esa "animadversión contra la política", característica de la mayoría de los filósofos, al precio de no actuar y no decir cómo actuar, pero gana el derecho de juzgar como "espectador del mundo", como custodio del interés de la humanidad.

Este argumento atribuye a la observación un rango especial, que otorga al mismo tiempo, a la filosofía una función al margen de la política activa. Platón pensaba que "los filósofos deberían llegar a ser reyes, no porque tuviesen una inclinación hacia la política, sino porque de este modo no serían gobernados por gente peor que ellos" y podría instaurarse una ciudad serena y pacífica, que constituye la condición más favorable para la vida del filósofo ${ }^{30}$. El argumento de Platón se sustenta en la idea de que el arte de gobernar (techné politiké) es del mismo tipo que otras technai, como el arte de navegar o el del zapatero, para los que, efectivamente, es preciso ser navegante y talabartero. Pero como ser en la ciudad, el filósofo es un igual a los demás ciudadanos, y no tiene prerrogativas especiales frente a los no sabios, a menos que el arte de gobernar se entienda como una competencia específica, propia del filósofo, en tanto "especialista" o entendido en el bien común, como quería creer Platón.

Una disposición hasta cierto punto similar se reproduce incluso en Hobbes, a pesar de no compartir el mismo argumento. Aunque está "más cerca de las preocupaciones políticas que ningún autor, Hobbes escribió su Leviatán para evitar los peligros de la política y garantizar en lo posible, la paz y la seguridad" ${ }^{31}$. En una vena en cierto modo análoga, Pascal sostiene que cuando los filósofos han escrito sobre política, "lo han

$31 \quad$ Conferencias sobre la filosofia politica de Kant, op. cit., p. 47 . ".

Conferencias sobre la filosofía política de Kant, op. cit., p. 47. "La 'publicidad' es uno de los conceptos clave del pensamiento político de Kant” (op. cit., p. 42). 
hecho como jugando; era esa la parte menos filosófica y menos seria de su vida... Si han escrito de política, era como si trataran de arreglar un hospital de locos; y si han aparentado hablar de ello como de una gran cosa, es que sabían que los locos a quienes se dirigían pensaban ser reyes y emperadores. Tenían en cuenta sus principios para moderar su locura, lo menos mal que se pudiera" 32 .

\section{El concepto de "mundo"}

La condición del ser político es el "ser en el mundo": una suerte de a priori del existir juntos; no hay politicidad sin "ser con otros" en un mundo compartido. En tanto pertenecemos solo a este mundo, el ser con otros es la verdadera esencia de los hombres. No es posible imaginar una forma más directa y eficaz de privar a los humanos de su humanidad, que desmundanizarlos, despojarlos de todo cuanto hace del mundo una morada, un lugar habitable para ellos: residencia, hogar, trabajo, familia, lugar social, ciudadanía.

Sin embargo, el concepto de mundo, que debía resituar el pensamiento, rescatándolo del confinamiento en el yo, consigue solo a medias devolver al mundo la validez que le suspende el método de las certezas de Descartes y la fenomenología de Husserl. El "ser en el mundo" repone el mundo suspendido y lo postula como constitutivo de la realidad humana, pero al mismo tiempo le niega validez al mundo común, de modo que conserva de la puesta entre paréntesis del mundo la suspensión de la validez de esa dimensión de la realidad humana que llamamos política. Los teóricos del liberalismo llegaron solamente a suponer una "naturaleza" apolítica del hombre - un estado de naturaleza prepolítico-, que les permite entender mejor lo político. Ser y tiempo, en cambio, desarrolla una suerte de apoliticidad ontológica que, a diferencia de la prepoliticidad metodológica de Rousseau o de Hobbes, aleja de la comprensión de la política.

Cuando Heidegger quiere validar una determinada política, lo hace atribuyéndole una "verdad interna" ${ }^{3}$. Sin un suplemento de espíritu, la política carece de verdad: de allí la distancia que Heidegger establece con la "política", al escribirla con la reserva de las comillas, salvo cuando posee espiritualidad. La filosofía interviene la política para procurar una verdad que ella misma no posee. De esa "verdad interna", solo sabe el filósofo -el sabio en esencias-, sabe de la esencialidad de esa política: los políticos nacionalsocialistas eran "gente demasiado indigentes en cuanto al pensar", por eso la necesidad de conducción espiritual, (eine geistige Führerschaft). Esta espiritualización representa, sin embargo, la renuncia al proyecto fundamental de inaugurar un pensar posmetafísico. La espiritualización

32 Pascal, Pensamientos. Aguilar, Buenos Aires, 1966, p. 133, № 294.

33 Ver Introducción a la metafísica, Nova, Buenos Aires, 1966; Discurso rectoral, en Marcos García de la Huerta, La técnica y el Estado moderno. Edeh, Santiago, 1980 pp. 27-36; Jacques Derrida, De l'esprit. Heidegger et la question, Galilée, Paris, 1987. 
de la política suprime la distancia entre política y filosofía; y es al mismo tiempo una "politización" del espíritu -la nacionalización del Geist-, que representa una re-caída en la metafísica desbaratada y "destruida" en la analítica.

Los juicios de Heidegger posteriores al desenlace de la Guerra están signados de pesimismo, pues él vivió ese momento como una derrota del Geist: "el desierto está creciendo", "las guerras mundiales no decidieron nada", "Rusia y América son lo mismo", "los vientos materialistas soplan del Este y del Oeste", "la marea de la desdicha sigue subiendo pero el hombre se achata cada vez más", "Stalin ya no tiene que declarar la guerra. Cada día gana una batalla. Pero no "se" dan cuenta. Para nosotros no hay escapatoria posible [...] aun si todo esto no se juega en la esfera de lo "político", que en sí misma está puesta fuera de juego hace tiempo por otras relaciones de ser y lleva una vida ilusoria", "por el hecho [de encontrarnos en el Centro de Europa] la fatalidad pesa de otro modo sobre nosotros. "Occidente" ya se había hundido del todo en un tiempo en que nadie hablaba aún de decadencia de Occidente. Desde hace largo tiempo, son otras "fuerzas" las que efectivamente están en obra [...] El curso de los acontecimientos que ensombrecen el planeta no podría ser una maquinación de individuos aislados, cuya función se limite a la de simples ejecutantes". "Ya solo un Dios puede salvarnos" ${ }^{34}$.

Arendt en su tesis sobre El concepto del amor en Agustín (1929), había esbozado una crítica a la idea de mundo en Heidegger. Consiste, básicamente, en que el concepto de mundo desarrollado en la analítica tiene una impronta "objetivista", que es otra cara del subjetivismo: consiste en su forma moderna en concebir la realidad humana según un modelo que prioriza la vida contemplativa y específicamente el yo pensante. Ser y tiempo avanzó significativamente en la dirección inversa, al establecer la anterioridad de la actividad sobre la teoría y la representación. Intentaba así superar el sesgo cosista, subjetivista, de la metafísica moderno-cartesiana, pero no logra librarse del lastre de la objetivación.

Esa tesis se proponía desarrollar un aspecto del mundo descuidado/olvidado en la analítica: "el mundo concebido como (lo ven) los amantes del mundo"35. Este "amor" al mundo se refiere sobre todo a la caritas cristiana, que en las Confesiones de Agustín tiene un lugar destacado, y no debe confundirse con cualquier otra forma de afecto, deseo o afición. Sin embargo, hay una dificultad inherente al intento de conciliar el amor al mundo y el amor al prójimo en el cristiano de la fe, porque "la fe arroja al individuo al aislamiento respecto de los demás individuos [...] saca del mundo al hombre, esto es, de una determinada comunidad de hombres, la civitas terrena" ${ }^{36}$.

34 La última cita está en Der Spiegel; la penúltima, en carta a Elisabeth Blochmann (3-III1947); la referente a Stalin, en carta a Jaspers (8-IV-1950); "el desierto crece" (Nietzsche) comentado en ¿Qué significa pensar? Nova, Buenos Aires, 1958; las otras citas, en Introducción a la metafísica. Nova, Buenos Aires, 1966.

35 Love in Saint Augustine. Chicago, University of Chicago Press, 1995, p. 178. (El concepto del amor de San Agustín. Tesis doctoral dirigida por Karl Jaspers, trad. A. Serrano, Encuentro, Madrid, 2001).

$36 \quad$ Love in Saint Augustine, op. cit., p. 53. 
Habría, entonces, un punto de encuentro entre el inter homines esse, el ser entre los hombres de las Confesiones y el "ser con" otros en el mundo, de Ser y tiempo. Si el concepto heideggeriano de mundo es impersonal y objetivista, carente de caritas, la visión agustiniana supliría esta carencia, a través de una forma de ser con otros o entre los hombres, que incluye la caritas y se expresa en el amor al prójimo. Sin embargo, la mundanidad equivale a la tentación para el cristiano de la fe. En La Condición humana, Arendt vuelve sobre este dilema haciendo explícita la dificultad que su tesis había obviado: la imposibilidad de una política cristiana. La abstención de los asuntos mundanos se sostiene en la convicción de que el mundo es mortal y la propia alma, inmortal. El mundo no puede perdurar; sin embargo, "encontrar un vínculo entre la gente suficientemente fuerte para reemplazar el mundo fue la principal tarea política de la temprana filosofía cristiana, y fue Agustín quien propuso fundar en la caridad no solo la "hermandad" cristiana sino todas las relaciones humanas. Pero esta caridad, a pesar de su carencia de mundanidad (worldlessness), corresponde claramente con la común experiencia humana del amor, y al mismo tiempo se distingue claramente de él por ser algo que es, como el mundo, entre los hombres: 'aun los ladrones tienen entre sí lo que ellos llaman caridad'. Esta sorprendente ilustración del principio político del cristianismo está de hecho muy bien elegido, porque el vínculo de la caridad entre los hombres, si bien es incapaz de fundar por sí mismo una esfera pública, es enteramente adecuado al principio cristiano esencial de la extra mundanidad (worldlessness) y es admirablemente idóneo para conducir por el mundo a un grupo de gente no mundana (worldless)" "37. La hermandad y la caridad no bastan ni pueden fundar la esfera pública porque son asuntos de índole privada. El mundo solo puede dar lugar a un espacio público si es perdurable o, por lo menos, durar más allá de la generación de los vivos. Un mundo mortal, concebido como lugar de tránsito de un alma, ella misma inmortal, no es el mundo público. De todos modos, en la ciudad moderna se da el desinterés por los asuntos del mundo y se expresa no solo en forma de religiosidad, sino mucho más frecuentemente en la cruda indiferencia hacia la política. La llamada "apoliticidad" suele entenderse en el sentido de no interesarse en la política y no tomar partido. Pero tiene un significado más radical que incluye las formas anteriores y consiste en no ser parte o pretender no pertenecer al cuerpo político. Este sentido de la "apoliticidad" es una nueva variante de la idea de "carencia de mundanidad".

\section{Referencias bibliográficas}

Arendt, Hannah (1988), La condición humana. Barcelona: Paidós. The Human Condition. Chicago University Press, 1958. (2002), La vida del espiritu. Buenos Aires: Paidós. The Life of the Mind, Nueva York: Harcourt Brace, 1978. 
(1996), Entre el pasado y el futuro. Barcelona: Península. Between Past and Future. Nueva York: Penguin Books, 1968.

(2010), Lo que quiero es comprender. Madrid: Trotta. Traducción en M. Hill (ed.) The Recovery of the public World. New York: St Martin's, 1979.

(2003), Conferencias sobre la filosofía politica de Kant. Barcelona: Paidós. Lectures on Kant's Political Philosophy. The University of Chicago Press, 1982.

(2000), Martin Heidegger, Correspondencia 1925-1975. Barcelona: Herder. Briefe 1925 bis 1975 und andere Zeugnisse. Francfort am Main: Vittorio Klosterman, 1999.

(2005), Ensayos de comprensión 1930-1954. Madrid: Caparrós Editores. Essays in Understanding 1930-1954, John (Comp.) Nueva York: Schocken Books.

(2008). Filosofía y política, en La promesa de la política. Barcelona: Paidós. Philosophy and Politics, en Social Research, Vol. 71, núm. 3, 2004.

(2001). El concepto del amor de San Agustín. Tesis doctoral dirigida por Karl Jaspers, trad. A. Serrano. Madrid: Encuentro. Love in Saint Augustine. Chicago: University of Chicago Press, 1995.

(1970), Heidegger octogenario. Revista de Occidente $\mathrm{N}^{\circ}$ 84, marzo. “Heidegger el zorro" en el Diario filosófico, Cuaderno XVII, julio de 1953. (2006), Diario filosófico 1950-1973. Barcelona: Herder.

Derrida, Jacques (1987), De l'esprit. Heidegger et la question. Paris: Galilée.

Faye, Emmanuel (2005), Heidegger, l'introduction du nazisme dans la philosophie. Paris: Albin-Michel.

García de la Huerta, Marcos (1980), La técnica y el Estado moderno. Santiago: Edeh. Heidegger, Martin (1961), Nietzsche. Neske.

(1962), Ser y tiempo. México: Fondo de Cultura Económica. (1990), Briefwechsel 1920-1963. Vittorio Klosterman, Francforty R. Piper, Munich, (Correspondance avec Karl Jaspers 1920-1963; Correspondance avec Elisabeth Blochmann 1918-1969. Paris: Gallimard, 1996.

(1966), Introducción a la metafísica. Buenos Aires: Nova. Einführung in die Metaphysik. Tübingen: Niemeyer, 1953.

(1966), Ya solo un Dios puede salvarnos. Entrevista en Der Spiegel, 23 de septiembre de 1966.

Kant, Emanuel (2004), Hacia la paz perpetua. Buenos Aires: Editorial Ladosur. Pascal, Blas (1966), Pensamientos. Buenos Aires: Aguilar. 